\title{
Comparing alternatives to canine rectal thermometry at the axillary, auricular and ocular locations
}

\author{
Eunice Kahng* and Cord Brundage \\ California Polytechnic University of Pomona, Pomona, CA 91768, USA
}

\begin{abstract}
Body temperature is an important component in the diagnosis and treatment of disease in canines. The rectal temperature remains the standard of obtaining temperature within the clinical setting, but there are many drawbacks with this method, including time, access, animal stress, and safety concerns. Interest in using infrared thermometry in canines to obtain body temperature has grown as animal scientists and veterinarians search for non-invasive and non-contact methods and locations of obtaining canine temperatures. Here, we review evidence on axillary, auricular, and ocular region canine thermometry and the degree to which measurements in these locations are representative of rectal temperature values. Instrumentation refinement and development, as well as morphologic differences, play an important role in the potential correlation between the rectal temperature and these other locations. These caveats have yet to be fully addressed in the literature, limiting the options for those seeking alternatives to rectal thermometry.

Keywords: Auricular, Axillary, Canine, Ocular, Thermometry.
\end{abstract}

\section{Introduction}

Obtaining and recording body temperature is essential in the proper diagnosis and treatment of canine patients. Core temperature is considered the gold standard of body temperature, as it closely reflects the temperature of the internal organs (Allegaert et al., 2014). The temperature at the hypothalamus is also a desired location to monitor, as this region is where body temperature is perceived (Cichocki et al., 2017). However, clinically, the most conventional method of taking a canine's temperature is through the rectal mucosa, as it continues to be a minimally invasive method that provides insight to core temperature (Kreissl and Neiger, 2015). Rectal thermometers have drawbacks, as they cannot be easily used on aggressive canids or ones with an infection or rupture of the anal mucosa (Kreissl and Neiger, 2015). To bypass the limitations caused by rectal temperatures, studies have been done using non - contact infrared (IR) thermometers, and focusing on alternative areas such as the axilla, auricular canal, and ocular regions of the canine (Gomart et al., 2014, Zanghi, 2016). Searches were made through institutional library databases such as Google Scholar and the National Center for Biotechnology Information. Searches were made using the following words: thermometry, temperature, auricular, ocular, surface, axillary, and canine. As a result, 50 papers were found. Studies that did not look at temperature measurements in axillary, auricular, and ocular locations were eliminated. As a result, 24 scientific studies were involved in this review.

Auricular IR thermometers have been gaining popularity as an alternative method to rectal thermometers. This
IR device measures the heat produced at the tympanic membrane of the ear (Kreissl and Neiger, 2015). The tympanic membrane shares the same blood flow as the hypothalamus, which further supports temperature measurement at this location (Kreissl and Neiger, 2015). Auricular thermometers, however, are very dependent on the correct positioning of the probe within the ear canal and must reach the tympanic membrane without damaging the ear (Gomart et al., 2014). There are also concerns of inaccurate reflection of body temperature in dogs presenting with otitis externa (González et al., 2002). Despite this concern, studies have shown that inflammation caused by otitis externa does not necessarily affect the temperature readings from auricular thermometers (Cichocki et al., 2017). Auricular thermometers provide more accurate readings if made specifically for veterinary use, as its curved shape allows the thermometer to have closer access to the canine's tympanic membrane (Gomart et al., 2014). Yet, these models tend to be more expensive in comparison to human thermometers, making it difficult for widespread adoption (Gomart et al., 2014). An alternative location to obtain temperature readings in canines is the axillary region. The decreased hair density in this particular region allows for digital thermometers to measure the surface temperature of the skin. Temperature readings are taken by placing the digital thermometer centrally within the axillary region, as far dorsally as possible (Cichocki et al., 2017). Axilla temperatures, however, have a poor correlation to rectal temperature (Cichocki et al., 2017).

Ocular surface temperature (OST) is a third region that has become an area of interest in obtaining body 
temperature. Ocular temperature studies originated in human ophthalmology as a faster method to diagnose common eye diseases such as keratoconjunctivitis sicca (Biondi et al., 2013). Ocular temperature is typically measured with an IR camera, but new studies have been done using non - contact IR thermometers to evaluate the temperature in canines (Kreissl and Neiger, 2015). We will be evaluating canine thermometry data taken from auricular, axilla, and ocular regions in comparison to rectal temperature.

\section{Instrumentation}

The first common device used to record body temperature was glass mercury thermometers. These thermometers measure temperature by equilibrating with the adjacent skin or mucosa (Teran et al., 2011). This method takes at least 3 minutes for the thermometer to fully reflect the temperature of the human or animal (Teran et al., 2011). Glass thermometers were used for several decades until the toxic effects of mercury contact were identified (Teran et al., 2011). Since then, digital thermometers have been readily used in clinical settings. These devices are the most common appliance utilized in veterinary clinics due to their affordability and ease of use (Kreissl and Neiger, 2015). Digital thermometers function by two forms of technology, equilibrium thermometry, and predictive thermometry (Mathis and Campbell, 2015). Equilibrium thermometry requires direct contact with the adjacent mucosa to allow the thermistor within the thermometer to use electrical resistance to calculate the body temperature, which can take up to 45 seconds (Kreissl and Neiger, 2015). Predictive thermometry involves direct contact with the body as well, but the rate of temperature change is recorded to algorithmically predict the final temperature of the canine, taking less than 15 seconds (Kreissl and Neiger, 2015). There have been no reported issues pertaining to these two methods, as they both provide comparable readings of body temperatures (Kreissl and Neiger, 2015).

IR technology has been used in the field of industry long before it has been used in clinical settings. The night vision was the first widespread use of IR in the military, and eventually IR technology was used to find victims hidden in debris from earthquakes and fires (Tan et al., 2009). IR cameras were introduced into the medical field in 1956, when scientists discovered that breast cancer could be detected by measuring elevated skin temperature (Lahiri et al., 2012). This technology has improved and expanded over the last 50 years and has become a popular tool in diagnosing diseases such as diabetic neuropathy, vascular disorders, dry eye syndromes, and metastatic liver disease, in addition to measuring the amount of radiation within the human body (Tan et al, 2009). In veterinary medicine, IR cameras have gained popularity within the equine field, using thermal imaging to detect injuries in sport horses (Figueiredo et al., 2013) Equine thermal imaging was originally used to detect areas of heat caused from inflammation, but has now expanded to discerning surface temperature responses to anesthetic and drug treatment in horses.

In addition to aiding in the diagnosis and treatment of certain diseases, IR thermometry is also being used to assess body temperature without bodily contact (Lahiri et al., 2012). There has been positive feedback regarding the use of non-contact IR thermometers in pediatric studies, as traditional rectal temperature readings tend to be stressful and unpleasant for children (Allegaert et al., 2014). Studies have now looked into using this same IR thermometry in clinical veterinary medicine, as an alternative to rectal thermometry. Temperaturecontrolled rooms, as well as user expertise play a role in the accuracy and consistency with IR temperature readings (Mathis and Campbell, 2015).

Coat length associated with different breeds can also affect thermoregulation. A study involving 47 racing greyhounds took thermal images of the tendo calcaneus, musculus gastrocnemius, musculus gracilis, and musculus biceps femoris portio caudalis before and after their races (Vainionpaa et al., 2012). The dogs raced four different distances, 325, 495, 560, and $785 \mathrm{~m}$. The post-race thermal images were significantly higher than the baseline thermal images when looking at the musculus gastrocnemius region. The other superficial temperatures were dependent on the measurement point on the body, but the reference interval for superficial temperature varied from $0.6^{\circ} \mathrm{C}$ to $2.1^{\circ} \mathrm{C}$ depending on the length of the race (Vainionpaa et al., 2012). The breed of the canine can also cause more heat loss due to their lack of fat and thin fur. It is thought that canines with longer fur tend to have a cooler surface temperature, due to the insulation of the coat (Kwon and Brundage, 2019). The thermal cameras showed that the canines did not suffer from severe hyperthermia after the races, which indicate that the intrinsic cooling system is effective (Vainionpaa et al., 2012).

The coat color of the animal may also cause variance in temperature readings with canines of the same breed. A study by McNicholl et al. (2016) in Australia found that greyhounds with darker coat colors such as black, blue, and brindle had higher post-race temperatures than of canines with lighter fur colors such as white and fawn. The mean post-race temperatures of the black, blue, and fawn greyhounds were $41.1^{\circ} \mathrm{C} \pm 0.4^{\circ} \mathrm{C}$, $41.1^{\circ} \mathrm{C} \pm 0.5^{\circ} \mathrm{C}$, and $41.1^{\circ} \mathrm{C} \pm 0.4^{\circ} \mathrm{C}$, and the mean post-race temperatures for fawn and white greyhounds were $40.9^{\circ} \mathrm{C} \pm 0.5^{\circ} \mathrm{C}$ and $40.8^{\circ} \mathrm{C} \pm 0.5^{\circ} \mathrm{C}$ (McNicholl et al., 2016). McNicholl et al. (2016) also found that lean canines may dissipate more heat than canines with less lean body mass. There was a positive correlation that was seen between body weight and post-race temperatures $\left(r^{2}=0.043\right)$. This could be due to the amount of energy that is used during greyhound races, since the energy requirements to move a body also increases with body weight. As a result, metabolic heat production also arises (McNicholl et al., 2016). 


\section{Axillary temperature}

Axillary temperature has become a popular region for temperature measurement due to its convenience (Gomart et al., 2014). Experiments done in humans suggests that axillary temperature is heavily dependent on body mass, tissue insulation, vasoconstriction, gender, age, and the environment (Gomart et al., 2014). Axillary temperatures are generally measured by placing the tip of the digital thermometer between the skin of the forearm and thorax within the axilla. There have been no reported studies looking at IR axillary temperature measurements in humans. Studies comparing rectal and axillary temperatures in canines are summarized in Table 1 . In clinical practice, $0.55^{\circ} \mathrm{C}$ $\left(1^{\circ} \mathrm{F}\right)$ is frequently added to axillary temperatures in canines to reflect core body temperature, but a recent study using Beagles $(n=26)$ found this to be inaccurate (Mathis and Campbell, 2015). The study found that axillary temperatures taken with a digital thermometer reflect values of $0.7^{\circ} \mathrm{C}-2.1^{\circ} \mathrm{C}$ lower than rectal temperature (Mathis and Campbell, 2015). The dogs were kept in a temperature-controlled room of $21.1^{\circ} \mathrm{C}-22.2^{\circ} \mathrm{C}$, with humidity levels at $22 \%-26 \%$ for 56 days to acclimate the animals. Despite these controlled conditions, there is little significance between rectal and axillary temperatures $\left(r^{2}=0.24\right)$ (Mathis and Campbell, 2015).

Another study looked at axillary temperatures from 250 dogs of various breeds (Gomart et al., 2014). Dogs were brought to the hospital for various health reasons and were given $30 \mathrm{~min}$ to acclimate to the hospital's temperature (Gomart et al., 2014). The mean rectal temperature, taken via digital thermometry, was $38.0^{\circ} \mathrm{C} \pm 0.85^{\circ} \mathrm{C}$ and ranged from $35^{\circ} \mathrm{C}$ to $40.4^{\circ} \mathrm{C}$ (Gomart et al., 2014). The mean axillary temperature was $37.0^{\circ} \pm 1.0^{\circ}$ and ranged from $33.4^{\circ} \mathrm{C}$ to $39.3^{\circ} \mathrm{C}$ (Gomart et al., 2014). Although these measurements were taken from different digital thermometers and uncontrolled conditions, the mean axillary temperatures had a stronger correlation $\left(r^{2}=0.70\right)$ compared to the first study (Gomart et al., 2014). The range for axillary temperatures, however, is much larger in the second study. This can be due to the dogs exhibiting more stress or illness from being in a veterinarian hospital. The calibration of the thermometer used in the second study was not stated, which could have also contributed to the range variation (Gomart et al., 2014). Mathis and Campbell (2015) found that temperature taken from dogs from an uncontrolled temperature environment exhibited inconsistent axillary measurement readings. A third study looked at dogs of assorted breeds $(n=50)$ admitted for various surgical procedures, such as tibial plateau leveling osteotomy, percutaneous laser disk ablation, and Hemilaminectomy (Cichocki et al., 2017). The dogs had axillary and rectal temperatures taken three times, once on the day of admittance into the hospital, once after the dog had recovered from surgery, and once more on the day the animal was discharged (Cichocki et al., 2017). No specific details on room temperature or the model of the thermometer were given. The mean for axillary temperatures was $37^{\circ} \mathrm{C} \pm 1.18^{\circ} \mathrm{C}$, which was statistically different than mean rectal temperature of $38^{\circ} \mathrm{C} \pm 0.88^{\circ} \mathrm{C}$ (Cichocki et al., 2017). This study had an $\left(r^{2}=0.42\right)$, reporting a poor correlation between the two temperature readings (Cichocki et al., 2017). This is important to note because axillary temperatures can have larger temperature fluctuations based on the environment the animal was in prior to recording surface skin temperature (Mathis and Campbell, 2015). It was also found that axillary temperatures have a better correlation with rectal temperatures in hyperthermic canines (Mathis and Campbell, 2015). This may be because surface temperatures are elevated in reflection to an elevated core body temperature (Mathis and Campbell, 2015). Collectively, evidence suggests axillary temperatures are an unreliable reflection of rectal body temperature. Axillary measurements have the potential to miss signs of hypothermia and hyperthermia, which can lead to a misinterpretation of this vital sign parameter. Further experiments should be carried out to determine the age and breed variant, which may offer some insight when this method is appropriate to use.

Table 1. Comparison of axilla temperature to rectal temperature in canines without physical activity. The same digital thermometer was used within each study to measure axilla and rectal temperatures. There is low correlation between the axilla and rectal temperature readings among the three studies.

\begin{tabular}{|c|c|c|c|c|c|c|c|c|}
\hline $\begin{array}{l}\text { Study: } \\
\text { Axilla }\end{array}$ & Subject & Female/Male & $\operatorname{Rectal}^{\circ} \mathrm{C}$ & Axilla ${ }^{\circ} \mathrm{C}$ & $r^{2}$ & $\begin{array}{c}\text { Exercise/ } \\
\text { Rest }\end{array}$ & $\begin{array}{l}\text { Device used: } \\
\text { Rectal }\end{array}$ & $\begin{array}{c}\text { Device used: } \\
\text { Axilla }\end{array}$ \\
\hline $\begin{array}{c}\text { Cichocki et al., } \\
2017\end{array}$ & 50 canines & $\begin{array}{c}26 \text { female } \\
24 \text { male }\end{array}$ & $38 \pm 0.88$ & $37.0 \pm 1.0$ & 0.42 & Rest & $\begin{array}{c}\text { Digital } \\
\text { Thermometer }\end{array}$ & $\begin{array}{c}\text { Digital } \\
\text { Thermometer }\end{array}$ \\
\hline $\begin{array}{l}\text { Mathis et al., } \\
2015\end{array}$ & 26 Beagles & $\begin{array}{l}17 \text { intact males } \\
9 \text { intact females }\end{array}$ & $38.72 \pm 0.37$ & $37.33 \pm 0.51$ & 0.24 & Rest & $\begin{array}{c}\text { Digital } \\
\text { Thermometer }\end{array}$ & $\begin{array}{c}\text { Digital } \\
\text { Thermometer }\end{array}$ \\
\hline $\begin{array}{l}\text { Gomart et al., } \\
2014\end{array}$ & $\begin{array}{c}250 \\
\text { hospitalized } \\
\text { canines }\end{array}$ & Unspecified & $38.0 \pm 0.85$ & $37 \pm 1.18$ & 0.49 & Rest & $\begin{array}{c}\text { Digital } \\
\text { Thermometer }\end{array}$ & $\begin{array}{c}\text { Digital } \\
\text { Thermometer }\end{array}$ \\
\hline
\end{tabular}




\section{Auricular temperatures}

Auricular thermometers are commonly used in human medicine as a relatively fast and validated method of approximating body temperature (Leduc et al., 2000). Auricular thermometers are usually IR and utilize pyroelectric sensors which detect electromagnetic radiation to calculate the temperature at or near the tympanic membrane (Sousa et al., 2011). The use of auricular temperature measurement in dogs has been fairly recent, and studies suggest that the reliability of auricular thermometers is dependent on user handling as well as the model of the thermometer used (González et al., 2002). Human auricular thermometers do not perform well in canine ear canals, as the horizontal and vertical canals curve downward in canines, unlike in the human ear (Cichocki et al., 2017). Studies have been carried out in canines to determine the similarity of auricular temperature to core body temperature. Studies comparing the rectal and auricular temperature in canines are summarized in Table 2. An experiment conducted by Sousa et al. (2011) used various canine breeds $(n=88)$ to test the acceptability of dogs towards auricular thermometers in comparison to rectal thermometers. It was found that the tolerance of canines to auricular thermometers was $89.7 \%$, but only $68.2 \%$ of dogs were tolerant of rectal measurements (Sousa et al., 2011). Dogs acclimated within the room for 30 minutes of $26.2^{\circ} \mathrm{C}$, with a humidity of $67.0 \%$ $\pm 17.2 \%$ (Sousa et al., 2011). Temperature readings were taken in the following order; rectal glass mercury temperature, human IR auricular temperature, rectal digital temperature, and finally rectal glass mercury thermometer (Sousa et al., 2011). The mean temperature documented from rectal readings were $38.8 \pm 0.4$ (glassmercury for 3 minutes), and $(38.7 \pm 0.4)$ (digital). The mean temperature for auricular readings was $39.0^{\circ} \mathrm{C} \pm$ $0.5^{\circ} \mathrm{C}$. A weak correlation was shown between auricular and rectal, as the $r^{2}$ value ranged from 0.343 to 0.372 (Sousa et al., 2011).

Another study done with 32 dogs, (16 Labradors and 16 Beagles) found that auricular temperatures can also vary based on the breed, time of day, and activity level (Zanghi, 2016). Auricular temperatures had a reference interval of $0.1^{\circ} \mathrm{C}-0.3^{\circ} \mathrm{C}$, which was lower than the rectal temperature in sedentary animals (Zanghi, 2016). Temperature readings are taken from animals presenting exercise-induced hyperthermia underestimated rectal temperature by $0.4^{\circ} \mathrm{C}-0.6^{\circ} \mathrm{C}$ (Zanghi, 2016). The correlation between the ear and rectal temperatures was $\left(r^{2}=0.615\right)$. This study is important to note because it suggests auricular temperatures may vary from rectal temperature based on the breed of the dog, as well as their activity level (Zanghi, 2016). This study also suggests that Labradors display consistently higher body temperatures in comparison to Beagles (Zanghi, 2016). It has been documented that smaller breeds tend to run higher temperatures than larger breeds. However, auricular temperatures may be more variant in breeds of dogs than size alone.

A study carried out by Hall and Carter (2017a; 2017b) examined the accuracy of auricular thermometers relative to rectal temperature. Rectal temperature was taken with a calibrated Vicks digital thermometer and Vet-Temp VT-150 Instant Ear Thermometer (Hall and Carter, 2017a). Auricular followed by rectal temperatures were taken from 24 canines following 20 minutes of unstandardized exercise consisting of a brisk walk, free run, or playtime with owners. Rectal temperature readings before exercise ranged from 38.3 \pm 0.39 ; auricular temperatures ranged from $37.9 \pm 0.53$. Following exercise, rectal temperature reading was $39.0 \pm 0.41$, and auricular temperature readings ranged from $38.6 \pm 0.50$ (Hall and Carter, 2017a). Auricular temperature underestimated rectal body temperature $82 \%$ of the trials, and only $68.4 \%$ of temperature readings fell within the $0.5^{\circ} \mathrm{C}$ of the differences between rectal and auricular temperature (Hall and Carter, 2017a). The great variability in auricular temperature could be due to the different shape of pinna presented in various dog breeds. The exercise was also unstandardized which could have led to some canines having a higher temperature than others.

Another study conveyed by Hall and Carter (2017a; 2017b) examined the reference range of auricular temperature in canines. Canines of various breeds $(n=157)$ were divided into two groups, pet canines and sport canines. An additional 30 canines were used to validate the results of the auricular temperature, which were separate from the initial experiment. Temperatures for pet canines $(n=32)$ were obtained indoors in a familiar area (at $21.2^{\circ} \mathrm{C}$ ), while canines competing in canicross ( $n=187$ ) had temperatures taken outdoors (in $8.9^{\circ} \mathrm{C}$ ). The reference range of temperature from canines in an indoor setting was $37.9^{\circ} \mathrm{C}$ (range $34.3^{\circ} \mathrm{C}-38.9^{\circ} \mathrm{C}$ ), while the temperature readings for canines in an outdoor setting was $37.7^{\circ} \mathrm{C}$ (range $36.2^{\circ} \mathrm{C}-39.1^{\circ} \mathrm{C}$ ). Carter found the reference interval of auricular temperature in canines to be $36.6^{\circ} \mathrm{C}-38.8^{\circ} \mathrm{C}$, which is lower than the company reported $\left(37.7^{\circ} \mathrm{C}-39.4^{\circ} \mathrm{C}\right)$ (Hall and Carter, 2017b).

\section{Ocular temperature}

Measurement of ocular temperature has been used widely in ophthalmology in humans to diagnose and treat diseases such as inflammation of the human lacrimal drainage system, glaucoma, and carotid artery stenosis (Oztas et al., 2016). The ocular temperature was first measured by a bolometer in 1968, which assessed the IR radiation and temperature of different regions of the eye globe (Oztas et al., 2016). There have been increasing studies done on horses relating to eye thermography, but fewer studies have been done measuring the eye temperature of canines (Biondi et al., 2013). A summary of these studies is listed in Table 3. OST has gained popularity as a potential method to obtain body temperature in veterinary medicine due 


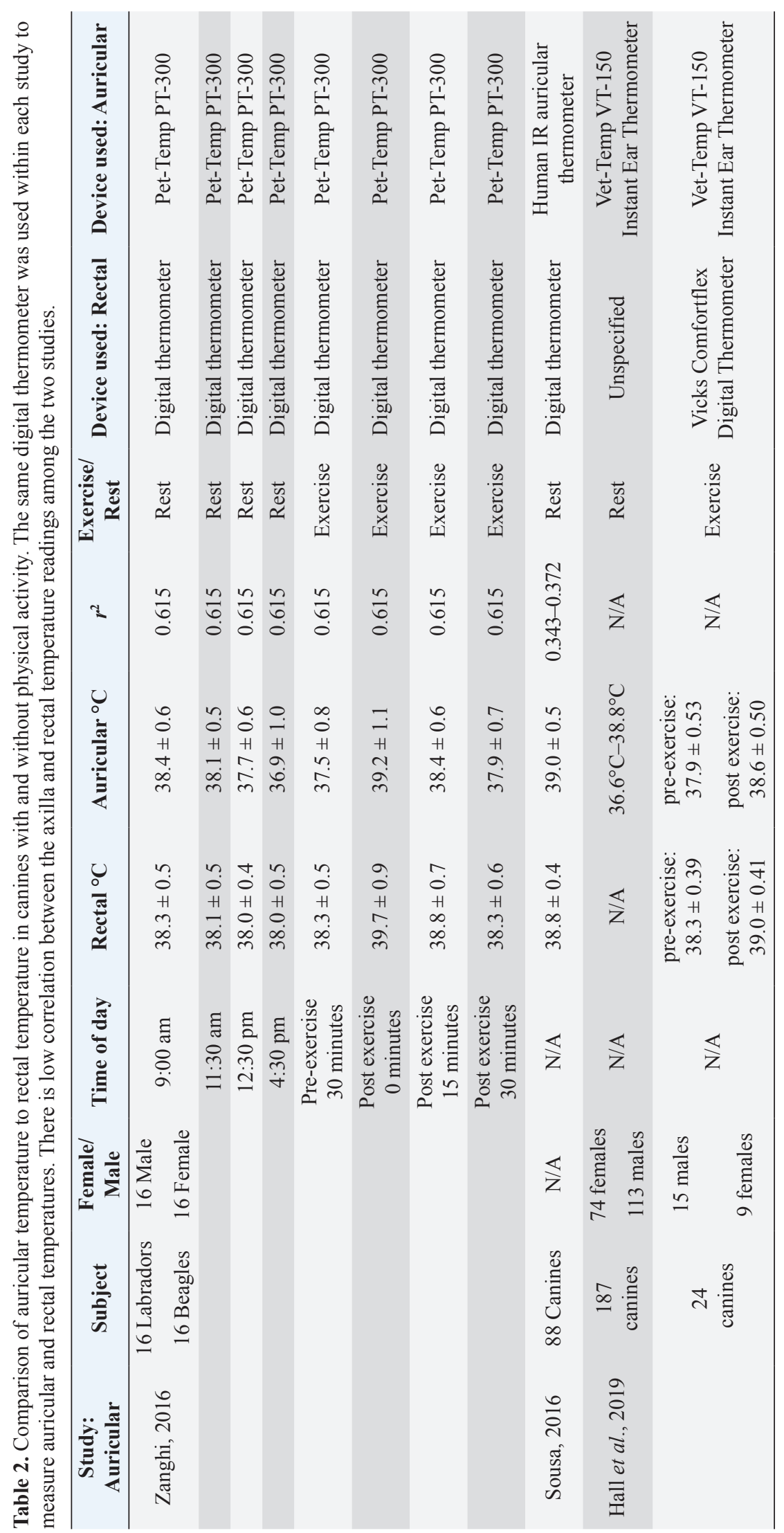


Table 3. Comparison of ocular temperature to rectal temperature in canines with and without physical activity. The same digital thermometer was used within each study to measure ocular and rectal temperatures. There is low correlation between the axilla and rectal temperature readings among the two studies.

\begin{tabular}{|c|c|c|c|c|c|c|c|c|c|}
\hline $\begin{array}{l}\text { Study: } \\
\text { Ocular }\end{array}$ & Subject & $\begin{array}{l}\text { Female/ } \\
\text { Male }\end{array}$ & Time of day & $\begin{array}{l}\text { Rectal } \\
{ }^{\circ} \mathbf{C}\end{array}$ & $\begin{array}{c}\text { Ocular } \\
{ }^{\circ} \mathrm{C}\end{array}$ & $r^{2}$ & $\begin{array}{c}\text { Exercise/ } \\
\text { Rest }\end{array}$ & $\begin{array}{c}\text { Device } \\
\text { used: Rectal }\end{array}$ & $\begin{array}{c}\text { Device used: } \\
\text { Ocular }\end{array}$ \\
\hline \multirow{8}{*}{$\begin{array}{c}\text { Zanghi, } \\
2016\end{array}$} & $\begin{array}{c}16 \\
\text { Labradors } \\
16 \\
\text { Beagles }\end{array}$ & $\begin{array}{c}16 \\
\text { males } \\
16 \\
\text { females }\end{array}$ & 9:00 am: & $38.3 \pm 0.5$ & $37.5 \pm 0.8$ & 0.145 & Rest & $\begin{array}{c}\text { Digital } \\
\text { thermometer }\end{array}$ & $\begin{array}{c}\text { Thermal IR } \\
\text { camera }\end{array}$ \\
\hline & & & 11:30 am: & $38.1 \pm 0.5$ & $37.3 \pm 0.9$ & 0.145 & Rest & $\begin{array}{c}\text { Digital } \\
\text { thermometer }\end{array}$ & $\begin{array}{c}\text { Thermal IR } \\
\text { camera }\end{array}$ \\
\hline & & & $12: 30$ pm: & $38.0 \pm 0.4$ & $36.7 \pm 0.8$ & 0.145 & Rest & $\begin{array}{c}\text { Digital } \\
\text { thermometer }\end{array}$ & $\begin{array}{c}\text { Thermal IR } \\
\text { camera }\end{array}$ \\
\hline & & & 4:30 pm: & $38.0 \pm 0.5$ & $36.9 \pm 0.9$ & 0.145 & Rest & $\begin{array}{c}\text { Digital } \\
\text { thermometer }\end{array}$ & $\begin{array}{c}\text { Thermal IR } \\
\text { camera }\end{array}$ \\
\hline & & & $\begin{array}{l}\text { Pre-exercise } \\
30 \text { minutes }\end{array}$ & $38.3 \pm 0.5$ & $37.5 \pm 1.1$ & 0.145 & Exercise & $\begin{array}{c}\text { Digital } \\
\text { thermometer }\end{array}$ & $\begin{array}{c}\text { Thermal IR } \\
\text { camera }\end{array}$ \\
\hline & & & $\begin{array}{l}\text { Post exercise } \\
0 \text { minutes }\end{array}$ & $39.7 \pm 0.9$ & $39.9 \pm 1.3$ & 0.615 & Exercise & $\begin{array}{c}\text { Digital } \\
\text { thermometer }\end{array}$ & $\begin{array}{c}\text { Thermal IR } \\
\text { camera }\end{array}$ \\
\hline & & & $\begin{array}{l}\text { Post exercise } \\
15 \text { minutes }\end{array}$ & $38.8 \pm 0.7$ & $38.7 \pm 0.9$ & 0.615 & Exercise & $\begin{array}{c}\text { Digital } \\
\text { thermometer }\end{array}$ & $\begin{array}{c}\text { Thermal IR } \\
\text { camera }\end{array}$ \\
\hline & & & $\begin{array}{l}\text { Post exercise } \\
30 \text { minutes }\end{array}$ & $38.3 \pm 0.6$ & $38.4 \pm 1.0$ & 0.615 & Exercise & $\begin{array}{c}\text { Digital } \\
\text { thermometer }\end{array}$ & $\begin{array}{c}\text { Thermal IR } \\
\text { camera }\end{array}$ \\
\hline $\begin{array}{c}\text { Kreissl } \\
\text { et al., } 2015\end{array}$ & $\begin{array}{c}300 \\
\text { Canines }\end{array}$ & $\begin{array}{c}\text { Un } \\
\text { specified }\end{array}$ & $\begin{array}{c}\text { Un } \\
\text { specified }\end{array}$ & 38.3 & 37.7 & 0.67 & Rest & $\begin{array}{c}\text { Digital } \\
\text { thermometer }\end{array}$ & $\begin{array}{c}\text { Non } \\
\text { contact IR } \\
\text { thermometer }\end{array}$ \\
\hline
\end{tabular}

to the advantages of not having to make direct contact with the animal (Collins et al., 2015). The ocular temperature has also been used as a method in detecting dry eye in canines as an alternative to the Schirmer tear test (Biondi et al., 2013).

Zanghi (2016) examined ocular temperature in reference to rectal temperature (Zanghi, 2016). Ocular temperatures were obtained using IR thermal camera, directed at both eyes in 16 Labradors and 16 Beagles. The reference range of ocular temperature was determined by creating a rectangular area that encompassed the whole eyeball, leaving around one $\mathrm{cm}$ outside of the eyelids (Zanghi, 2016). The temperature of the eyes and rectum were taken at four different times throughout the day before exercise (9:00 am, 11:30 am, $12: 30 \mathrm{pm}$, and 4:30 pm). The dogs were housed within an indoor kennel, with the ambient temperature of $78^{\circ} \mathrm{F}-80^{\circ} \mathrm{F}$ and humidity being at $78 \%$. The reference interval for ocular temperature was determined from the four data collection times (9:00 am, 11:30 am, 12:30 pm, and $4: 30 \mathrm{pm}$ was $37^{\circ} \mathrm{C} \pm 0.1^{\circ} \mathrm{C}$ in Labradors and $36.9^{\circ} \mathrm{C} \pm 0.1^{\circ} \mathrm{C}$ in Beagles. It was found that Labradors also had a higher rectal temperature $\left(38.3^{\circ} \mathrm{C} \pm 0.1^{\circ} \mathrm{C}\right)$ in comparison to Beagles $\left(37.8^{\circ} \mathrm{C} \pm 0.1^{\circ} \mathrm{C}\right)$.

The reference range for rectal temperatures was usually one degree higher than in ocular temperatures. Data was also obtained from the animals after exercise, ranging from 30 minutes before exercise to 0,15 , and 30 minutes after exercise. The data collected from canines after exercise had a closer connection to rectal and ocular temperature immediately after exercise (Zanghi, 2016). However, after 15-30 minutes of postexercise rest, ocular readings became similar to preexercise readings. Correlation for both pre and postexercise was not significant $\left(r^{2}=0.145\right)$.

Another study performed with various breeds $(n=$ 300) also tested ocular temperature in relation to rectal temperature using a non-contact IR ocular thermometer. Rectal temperature was taken by a digital thermometer and ocular temperature was taken by placing a noncontact IR thermometer perpendicular to the left cornea (Kreissl and Neiger, 2015). The dogs were allowed to adjust to the indoor room for 30 minutes of unspecified room temperature. Both thermometers were also compared to a calibrated thermometer before the experiment took place. The mean temperature readings for ocular temperature with an experienced handler was $37.7^{\circ} \mathrm{C}$, with a range of $\left(35.9^{\circ} \mathrm{C}-40.1^{\circ} \mathrm{C}\right)$ (Kreissl and Neiger, 2015). The mean rectal temperature was $38.3^{\circ} \mathrm{C}$, with a range of $\left(35.3^{\circ} \mathrm{C}-41.1^{\circ} \mathrm{C}\right)$ (Kreissl and Neiger, 2015). The correlation between IR and rectal readings was higher than the first study $\left(r^{2}=0.67\right)$. This could be due to the use of instruments that were better equipped to measurement eye temperature. 


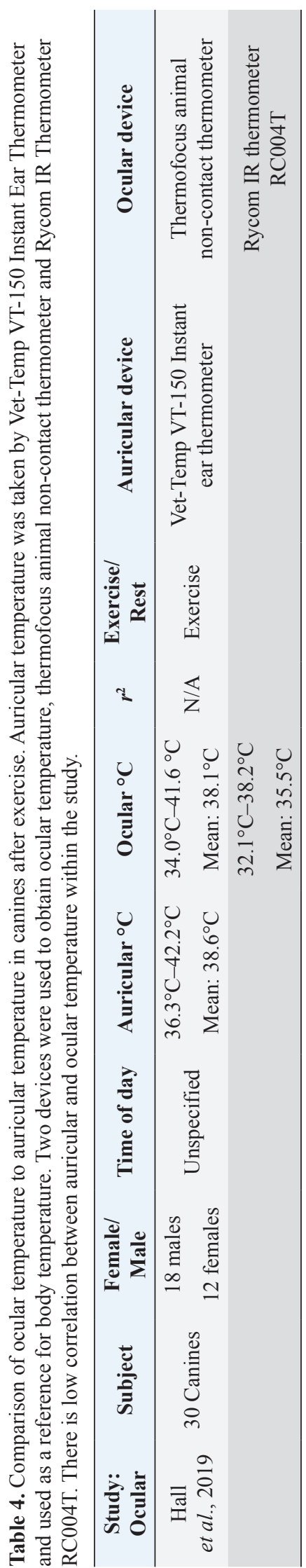

A study carried out by Hall et al. (2019), Fleming, and Carter examined IR ocular temperature in comparison to auricular temperature. Studies comparing ocular and auricular temperatures in canines are summarized in Table 4. Active canines $(n=30)$ of various breeds participating in canicross were used; there was no specification as to the ambient temperature or location. Ocular temperatures were taken with two different devices, Thermofocus Animal non-contact thermometer and Rycom non-contact IR thermometer model RC004T. The auricular temperature was taken first (Vet-Temp VT-150) followed by immediately measuring ocular temperature using the Rycom device by the same handler (Hall et al., 2019). The auricular temperature readings ranged from $36.3^{\circ} \mathrm{C}$ to $42.2^{\circ} \mathrm{C}$ (median $=38.6^{\circ} \mathrm{C}$ ) and the temperatures read from the Thermofocus device were $34.0^{\circ} \mathrm{C}-41.6^{\circ} \mathrm{C}$ (median $=$ $38.1^{\circ} \mathrm{C}$ ) (Hall et al., 2019). The Rycom device read $32.1^{\circ} \mathrm{C}-39.1^{\circ} \mathrm{C}\left(\right.$ median $\left.=37.4^{\circ} \mathrm{C}\right)$. There was a low correlation between auricular and ocular temperature (Hall et al., 2019).

A study carried out in humans by Jen Tan has found that ocular temperature varies between young and older patients. Older patients were found to have a lower corneal temperature, which was speculated to be due to a slower metabolism (Tan et al., 2011). Further study should be performed in canines to examine if OST also varies in older animals, and the accuracy of ocular temperature as a reflection of core body temperature.

\section{Conclusion}

Based on the current literature, axillary, auricular, and ocular do not show a strong correlation to rectal temperature. Studies regarding temperature obtained from axillary regions could further be improved by testing the effects fluctuating ambient temperatures upon surface temperature readings, as well as the effect of coat color and coat length. The variability of canine pinna can also affect auricular temperature readings, and further studies should be performed to determine if breed variability alone can resolve correlation issues with rectal temperature. Ocular temperature readings have been used mainly in horses and people, but few studies have occurred using canines. Ocular temperature studies could improve by finding the optimal distance and ambient temperature needed to provide accurate readings of surface ocular temperature. References ranges of each location must also be established with each diagnostic tool (Sousa, 2016). Based on the current evidence, rectal thermometry remains the only reliable standard of estimating canine core body temperature in clinical veterinary medicine.

\section{References}

Allegaert, K., Casteels, K., van Gorp, I. and Bogaert, G. 2014. Tympanic, infrared skin, and temporal artery scan thermometers compared with rectal 
measurement in children: a real-life assessment. Curr. Ther. Res. 76, 34-38.

Biondi, F., Dornbusch, P.T., Sampaio, M. and MontianiFerreira, F. 2013. Infrared ocular thermography in dogs with and without keratoconjunctivitis sicca. Vet. Ophthal. 18, 1-15.

Cichocki, B., Dugat, D. and Payton, M. 2017. Agreement of axillary and auricular temperature with rectal temperature in systemically healthy dogs undergoing surgery. J. Am. Anim. Hosp. Assoc. 53, 291-296.

Collins, H.C., Leatherwood, J.L., Anderson, M.J., Beverly, M.M., Yildiz, F.X., Walker, N.L. and Pritchett, K.B. 2015. Relationship of ocular and rectal temperature as indicators of health status in horses. J. Equine Vet. Sci. 35, 423.

Figueiredo, T., Dzyekanski, B., Pimpão, C., Silveira, A., Capriglione, L. and Michelotto, P. 2013. Use of Infrared Thermography to Detect Intrasynovial Injections in Horses. J. Equine Vet. Sci. 33, 257260.

Gomart, S.B., Allerton, F.J. and Gommeren, K. 2014. Accuracy of different temperature reading techniques and associated stress response in hospitalized dogs. J. Vet. Emerg. Crit. Care 24, 279-285.

González, A.M., Mann, F.A., Preziosi, D.E., Meadows, R.L. and Wagner-Mann, C.C. 2002. Measurement of body temperature by use of auricular thermometers versus rectal thermometers in dogs with otitis externa. J. Am. Vet. Med. Assoc. 221, 378-379.

Hall, E. and Carter, A. 2017a. Comparison of rectal and tympanic membrane temperature in healthy exercising dogs. Comp. Exer. Phys. 13, 37-44.

Hall, E. and Carter, A. 2017b. Establishing a reference range for normal canine tympanic membrane temperature. Vet. Nurs. J. 32, 369-373.

Hall, E., Fleming, A. and Carter, A. 2019. Investigating the use of non-contact infrared thermometers in cats and dogs. Vet. Nurse. 10, 109-115.

Kreissl, H. and Neiger, R. 2015. Measurement of body temperature in 300 dogs with a novel non-contact infrared thermometer on the cornea in comparison to a standard rectal digital thermometer. J. Vet. Emerg. Crit. Care. 25, 372-378.

Kwon, C. and Brundage, C. 2019. Quantifying body surface temperature differences in canine coat types using infrared thermography. J. Therm. Biol. 82, $18-22$.
Lahiri, B.B., Bagavathiappan, S., Jayakumar, T. and Philip, J. 2012. Medical applications of infrared thermography: A review. Infra. Phys. Technol. 55, 221-235.

Leduc, D., Woods, S. and Community Paediatrics Committee. 2000. Temperature measurement in paediatrics. J. Paediatr. Child Health. 5, 273-278.

Mathis, J. and Campbell, V. 2015. Comparison of axillary and rectal temperatures for healthy Beagles in a temperature and humiditycontrolled environment. Am. J. Vet. Res. 76, 632-636.

McNicholl, J., Howarth, G. and Hazel, S.J. 2016. Influence of the environment on body temperature of racing greyhounds. Front Vet. Sci. 3, 53.

Oztas, Z., Selver, O.B., Akkin, C., Canturk, E. and Afrashi, F. 2016. Correlation of handheld infrared skin thermometer and infrared videothermography device for measurement of corneal temperature. Eye Contact Lens. 42, 202-205.

Sousa, M.G. 2016. Measuring body temperature: how do different sites compare? Vet. Rec. 178, 190-191.

Sousa, M.G., Carareto, R., PereiraJunior, V. and Aquino, M. 2011. Comparison between auricular and standard rectal thermometers for the measurement of body temperature in dogs. Can. Vet. J. 52, 403406.

Tan, J.H., Ng, E.Y.K., Acharya, U.R. and Chee, C. 2009. Infrared thermography on ocular surface temperature: A review. Infra. Phys. Technol. 52, 97-108.

Tan, J.H., Ng, E.Y.K. and Acharya, U.R. 2011. Evaluation of topographical variation in ocular surface temperature by functional infrared thermography. Infra. Phys. Technol. 54, 469-477.

Teran, C.G., Torrez-Llanos, J., Teran-Miranda, T.E., Balderrama, C., Shah, N.S. and Villarroel, P. 2011. Clinical accuracy of a non-contact infrared skin thermometer in pediatric practice. Child. Care Health Dev. 38, 471-476.

Vainionpaa, M., Tienhaaara, E.P., Raekallio, M., Junnila, J., Snellman, M. and Vainio, O. 2012. Thermographic imaging of the superficial temperature in racing greyhounds before and after the Race. Sci. World J. 2012, 1-6.

Zanghi, B.M. 2016. Eye and ear temperature using infrared thermography are related to rectal temperature in dogs at rest or with exercise. Front Vet. Sci. 3, 111. 